\title{
Crítica, política e psicologia social: A mudança social e o lugar da ação intelectual na luta política
}

Frederico Alves Costa. Universidade Federal de Alagoas.

Marco Aurélio Máximo Prado. Universidade Federal de Minas Gerais.

\section{Resumo}

O objetivo do artigo é refletir sobre a relação entre crítica, política e psicologia social através da análise de duas concepções teóricas - conscientização, consciência política -, referentes à noção de mudança social e do lugar da ação intelectual, construídas na psicologia social brasileira a partir da "crise" deste campo de conhecimento e da proposição de deslocamentos teóricos nestas concepções. A crítica é entendida como uma prática que torna visível modos distintos de articular ciência e política, a política como vinculada à dimensão do político e a psicologia social como um campo do conhecimento constituído na disputa entre modos de representação da realidade. A discussão contribui para a retomada da noção de hegemonia na psicologia social brasileira em uma perspectiva não essencialista, fundamentada em trabalhos de Ernesto Laclau e de Chantal Mouffe, possibilitando repensar a noção de mudança social e o lugar da ação intelectual na luta política na atualidade.

Palavras-chave: psicologia social; crítica; política; mudança social; poder.

\begin{abstract}
Critique, politics and social psychology: The social change and the intellectual in the political struggle. This paper aims to discuss the relationship between critique, politics and social psychology. We analyze two existing theoretical conceptions in Brazilian critical social psychology about the idea of the social change, specifically about two models - critical consciousness and political consciousness, formulated from the Latin-American social psychology "crisis". We understand the critic as a practice that makes visible different ways to link science and politics, the politics as articulated to the dimension of the political, and the social psychology as a field of knowledge formed from the dispute over the representation of reality. The discussion contributes to the resumption of the notion of hegemony in Brazilian critical social psychology from a non-essencialist perspective by Ernesto Laclau and Chantal Mouffe, which allows rethinking about the notion of social change and the role of intellectual in the political struggle.
\end{abstract}

Keywords: social psychology; critique; politics; social change; power.

\section{Resumen}

Crítica, política y psicología social: El cambio social y la función del intelectual en la lucha política. El artículo tiene como objetivo principal traer la reflexión sobre la relación entre la crítica, la política e la psicología social. Desde un análisis de perspectivas teóricas del cambio social en la psicología social brasileña, e de los modelos de concientización e de consciencia política emergidos a partir de la crisis de la psicología social, el artículo propone algunos cambios teóricos entre las perspectivas. La idea de crítica es tomada como una practica de hacer visible los distintos modos de articulación entre ciencia e la política, esta desde una perspectiva de la dimensión de lo político e la psicología social entendida como un campo de conocimiento en el cual están en disputas muchos modos de representación de la realidad. La principal contribución que se visa en este artículo es la retomada de la concepción de la hegemonía en el interior de la psicología social crítica brasileña en una perspectiva no fundacionista desde el trabajo de Ernesto Laclau y Chantal Mouffe, que nos ayude reflexionar sobre el cambio social y el papel de lo intelectual en la lucha política en la contemporaneidad.

Palabras clave: psicología social; crítica; política; cambio social; poder. 
A discussão sobre a relação entre crítica, política e psicologia social implica a reflexão sobre a concepção de ciência em torno da qual se sustenta a produção da psicologia social, sendo a crítica entendida como uma prática que torna visíveis modos distintos de articular conhecimento e política.

Compreendemos que todo e qualquer conhecimento, inclusive o científico, é situado social e historicamente, sendo a política entendida como constitutiva da produção científica, pois os fenômenos sociais são construídos analiticamente em um campo de disputa pela concepção da realidade. Essa disputa não é ingênua, é orientada eticamente pela afirmação de um imaginário social, vinculando teoria e prática.

A crítica, ao problematizar a relação entre ciência e concepção da realidade, está sujeita às condições históricas do momento em que é realizada e do qual faz parte, de modo que "a crítica de um tempo pode converter-se em um objeto criticado" (Montero, 2010, p. 179, tradução nossa), possibilitando outras leituras da realidade em relação àquilo que já se produziu.

O argumento defendido neste artigo é que foi fundamental a crítica realizada pela psicologia social latino-americana nas décadas de 1970 e 1980 à psicologia social dominante, no contexto histórico denominado "crise" da psicologia social. Contudo, deslocamentos na proposta da psicologia social latinoamericana podem contribuir para uma atualização da crítica a fim de explicitar limitações na concepção da mudança social e do lugar da ação intelectual na relação entre teoria e prática. Abordaremos estes deslocamentos centrando-nos em duas concepções teóricas presentes na psicologia social brasileira - baseadas nas noções de conscientização e de consciência política - recorrendo-nos à dimensão do político a partir de uma perspectiva não essencialista de sujeito e de história, fundamentada no pensamento de Ernesto Laclau e de Chantal Mouffe.

Este argumento articula-se em torno de três debates centrais: a) a crítica à ideia de fundamento último na explicação do sujeito e da história; b) a crítica à noção de racionalidade como determinante na construção do sujeito político; c) diante dessas críticas, a compreensão do lugar da ação intelectual na atualidade, questão cara à psicologia social desde o momento da "crise" desta ciência.

\section{A Crítica na Emergência da Crise da Psicologia Social Brasileira}

Na emergência da "crise" da psicologia social, nas décadas de 1970 e 1980, momento em que se observou uma crítica à influência do positivismo nas ciências sociais, diferentes teóricos questionaram o modelo de psicologia social dominante, majoritariamente desenvolvido nos Estados Unidos (Álvaro \& Garrido, 2006; Camino \& Torres, 2011; Farr, 2006). Modelo que apresentava como base a psicologia social behaviorista experimental e que a partir, sobretudo, da década de 1960 , instituiu-se como uma psicologia social cognitiva experimental.

Segundo Rodrigues (1985), que se identifica com a linha da psicologia social cognitiva, o domínio do cognitivismo era indiscutível na psicologia social. Remetendo-se ao capítulo de Markus e Zajonc, publicado na edição de 1985 do Handbook of Social Psychology, ressalta a compreensão destes autores de que a psicologia social e a psicologia social cognitiva eram quase sinônimos, sendo praticamente todos os investigadores impelidos a verem os fenômenos psicossociais sob a perspectiva cognitiva.

A psicologia social dominante, influenciada pelo positivismo, baseava-se na experimentação, na busca por um conhecimento objetivo e neutro e na construção de leis universais. No que tange à relação entre indivíduo e sociedade, centrava-se na análise dos níveis intra e/ou interindividual, priorizando os aspectos da socialização relativos à adaptação social, ao conformismo social, em detrimento daqueles ligados à transformação social. Ademais, esse modelo concebia a relação entre teoria e prática como uma aplicação da teoria a problemas sociais, a qual era construída a partir de pesquisas experimentais que idealizavam resultados universais. Estes aspectos foram salientados na crítica tanto de autores europeus quanto latino-americanos (Lane 1987a ; Moscovici, 2003).

Na América Latina, até a emergência da "crise, observava-se, predominantemente, a importação a-crítica desse modelo dominante de psicologia social. Construído, sobretudo, a partir da realidade norteamericana, mas pretendendo-se universal, esse modelo encontrava-se distante do contexto histórico de ditaduras militares e de extrema desigualdade social vividos nos países latino-americanos (Bomfim, 2003; Camino,1996; Sandoval, 2002). 
Com a "crise", uma concepção alternativa de ciência foi proposta. Na crítica à neutralidade científica, defendeu-se um posicionamento político da ciência direcionado à transformação social. Na crítica à concepção do indivíduo como unidade de sentido, passou-se a concebê-lo como sujeito social e histórico. $\mathrm{Na}$ crítica à artificialidade da produção de conhecimento em laboratório e à distinção entre teoria e prática, o desafio que caracterizou a psicologia social crítica na década de 1980 foi a indissociabilidade entre teoria e prática (Lane, 1995):

\begin{abstract}
Mediante uma prática do psicólogo em comunidades se procurou uma sistematização teórica, e, por meio de pesquisas sobre o comportamento político, buscou-se também encontrar formas de atuação para que, em ambos os casos, houvesse transformações significativas para as populações desfavorecidas da América Latina (p. 71).
\end{abstract}

Essa compreensão distinguia-se da concepção de "tecnologia social" também defendida na década de 1980, baseada na "utilização dos achados científicos das Ciências Sociais a fim de resolver problemas sociais" (Rodrigues, 1985, p. 19). A concepção de tecnologia social mantinha a separação entre teoria e prática pesquisa básica, ciência neutra que procura relações nãoaleatórias entre variáveis; tecnologia social, aplicação dos achados científicos - e, segundo Codo (1985), na crítica à Jacobo Varela, "constitui uma autêntica 'receita' para resolver problemas sociais" (p. 21), promovendo ajustamento e adaptação do comportamento.

Essa crítica realizada na América Latina foi, por um lado, importante para a afirmação da dimensão social e histórica do conhecimento e do compromisso éticopolítico do intelectual na promoção da mudança social, questionando as dicotomias indivíduo-sociedade, teoriaprática, ciência-política. Passou-se a visar a produção de conhecimento atrelada à consciência da população sobre os determinantes políticos das relações de dominação e ao resgate do seu papel na construção da sociedade, entendendo os sujeitos como participantes e não como objetos das pesquisas.

Por outro lado, consideramos necessário discutir compreensões de mudança social presentes na psicologia social crítica brasileira construída a partir dessa perspectiva emergente na década de 1980. Abordaremos duas concepções sobre a mudança social tendo como orientação a discussão sobre a politização das relações sociais e sobre o lugar da ação intelectual na luta política: uma concepção centrada na noção de conscientização social, na qual focaremos a presença de um fundamento último da realidade; outra centrada na noção de consciência política, na qual focaremos o aspecto da racionalidade.

É importante ressaltarmos que ainda que o debate apresentado remeta-se a propostas desenvolvidas por Silvia Lane e por Salvador Sandoval, respectivamente, não foi nosso intuito explorarmos detidamente a construção teórica destes autores, mas sim abordarmos aspectos fundamentais a suas concepções referentes à politização das relações sociais e ao lugar da ação intelectual. Tomamos essas duas concepções por serem referências que fortemente explicitaram a importância destes debates na Psicologia Social Brasileira desde a emergência da "crise".

\section{O Político como Elemento Epistemológico na Atividade Crítica}

Consciência como elemento central à mudança social. O conceito de consciência tem sido fundamental à psicologia social crítica latino-americana para a compreensão da mudança social. No caso brasileiro, de modo geral, podemos considerar duas compreensões que se assemelham pela concepção dos sujeitos políticos como positividades, isto é, como definidos anteriormente ao conflito a partir da atribuição de qualidades intrínsecas a eles, que os define pelo o que são e o que querem, e pela racionalidade como elemento mediador da politização das relações sociais.

Uma compreensão concebe a mudança social a partir da noção de conscientização dos indivíduos, sob influência do marxismo ${ }^{1}$, entendendo as relações de produção como fundamento último da realidade. Os sujeitos políticos são determinados pela localização que ocupam nessas relações, mesmo nos casos em que se observa uma concepção que expande o terreno da luta de classes ao compreender as "classes subalternas", e não apenas o proletariado, como o sujeito da mudança social. Neste sentido, podemos observar a compreensão de Lane e Sawaia (1991):

Não estamos aqui defendendo o corporativismo do operariado ou afirmando que a transformação se realiza somente através de sua ação. Aceitamos a perspectiva gramsciana de convergência das lutas da classe subalterna e classe operária. Uma das propostas que aplaudimos na PP [pesquisa participante] é sua tentativa de superar a visão estreita da esquerda radical, que faz da classe operária um dogma estéril dentro da nossa 
realidade (inclusive em minha pesquisa trabalho com o favelado). Queremos apenas marcar, mais uma vez que, para Marx não existiria revolução sem teoria revolucionária e a teoria revolucionária no capitalismo só é possível na ótica de quem produz a mais-valia. Essa última categoria deve estar presente na definição do sujeito da pesquisa, pois é ele quem estabelece a relação entre os diferentes setores da massa trabalhadora e lhes dá unicidade (pp. 48-49, grifo nosso).

Lane (1987b) ao conceber que a subjetividade é construída no terreno ideológico (superestrutura), tendo a linguagem o papel da mediação ideológica, compreende que a psicologia social necessita "pesquisar as representações (linguagem, pensamento) juntamente com as ações de um indivíduo, este definido pelo conjunto de suas relações sociais, para se chegar ao conhecimento de seu nível de consciência/alienação num dado momento" (p. 44).

O processo de conscientização é entendido pela autora a partir do desencadeamento pelo indivíduo de uma "consciência de si" (categoria psicológica) indissociada da "consciência de classe" (categoria sociológica). Ao tomar consciência das determinações históricas das relações sociais, o indivíduo reconhece-se membro de um mesmo grupo, o qual se encontra inserido nas relações de produção que estruturam a sociedade: "O indivíduo consciente de si, necessariamente, tem consciência de sua pertinência a uma classe social" (Lane, 1987b, p. 42). Segundo Lane (1987c), "as relações de produção geram a estrutura da sociedade, inclusive as determinações socioculturais, que fazem a mediação entre o homem e o ambiente" (p. 82, grifo nosso).

Outra concepção que abordamos, diferente da anterior, não ressalta as relações de produção como um fundamento último da realidade. Esta concepção pode ser localizada no interior da compreensão que nas décadas de 1980 e 1990 houve uma retomada de estudos psicossociológicos no campo das ações coletivas. Estes estudos, ainda que sustentados pela mesma base de racionalidade da Teoria de Mobilização de Recursos (mediação racional), passaram a considerar o sujeito político não somente em sua racionalidade instrumental, salientando uma perspectiva mais psicossocial. Para tanto, recorreram a categorias como identidade e consciência dos atores sociais, à constituição das representações dos atores sociais nas análises sobre oportunidades políticas e mobilização social.

Podemos considerar nesta segunda concepção de mudança social a compreensão de Salvador Sandoval sobre a análise da consciência política dos indivíduos² ${ }^{2}$ Sandoval reconhece a pluralidade de sujeitos políticos, mas os define anteriormente ao conflito em termos de uma identidade social e de uma subjetividade racional.

O autor compreende as categorias sociais de pertença dos indivíduos como "agrupamentos de pessoas que se distinguem de outros por compartir os mesmos critérios ou atributos, por exemplo, características étnicas-raciais, de local ou região de origem, de condições socioeconômicas e situações de vida, ocupacionais, etc." (Sandoval, 1989, p. 71). A relação política é entendida como uma relação na qual a identificação do adversário é pensada a partir da oposição entre interesses de categorias sociais distintas, constituídas anteriormente ao conflito: "Uma chave para a consciência política que apoia a ação coletiva é o sentimento de uma relação adversária entre si mesmo e outro grupo ou categoria social" (Sandoval, 2015, p. 204).

A vinculação a uma teoria racionalista aponta para a naturalização da motivação dos indivíduos para atuar, orientando-se a partir da maximização do bem-estar individual e do interesse particular da identidade social a qual ele é localizado e se reconhece na sociedade, buscando o grupo de pertença mobilizar recursos que propiciem condições para o alcance dos interesses comuns ao grupo (Sandoval, 1989).

O modelo de consciência política desenvolvido por Sandoval, primeiramente publicado no ano 2000, demonstra a preocupação com a análise psicossocial do comportamento político, ressaltando a dimensão das crenças e valores dos indivíduos, entendidos como sujeitos sociais e históricos, juntamente com a manutenção do caráter racional da participação política.

Consideremos duas dimensões deste modelo. Uma dimensão é a vontade de agir coletivamente, que se remete à predisposição do indivíduo para atuar coletivamente a fim de reparar injustiças sociais cometidas contra ele. Essa dimensão, segundo Sandoval (2015), "é uma noção bastante modificada da teoria da escolha racional" (p. 207), contudo, mantém-se no interior de uma perspectiva racionalista: os aspectos que constituem a vontade de agir são a relação custo-benefício, perdas-ganhos materiais, riscos do engajamento em ações coletivas e "avaliação do indivíduo da capacidade da organização do movimento para implementar as ações coletivas propostas" (p. 207).

Outra dimensão é a eficácia política, que se remete aos sentimentos dos indivíduos sobre sua capacidade de intervir. Sandoval (2015) recorre à teoria da atribuição 
para explicar a distinção da conduta dos indivíduos: a atribuição de causalidade a forças transcendentais leva a reações conformistas e submissas; a atribuição de causalidade ao próprio indivíduo leva a soluções individuais; a atribuição de causalidade a ações de outros indivíduos ou grupos "contribui para que indivíduos se sintam capazes de se tornarem atores determinados a mudar suas vidas" (p. 206).

Segundo Silva (2007) e Gonçalves (2008), Sandoval propõe quatro níveis distintos de consciência política que vão da consciência do senso comum à consciência revolucionária. Segundo Silva (2007), trata-se de um modelo de desenvolvimento consciente dos indivíduos. De acordo com Sandoval (2015), a noção de consciência traz como lugar central a "'conscientização' como o processo pelo qual os indivíduos alteram suas consciências frente aos acontecimentos das realidades vividas por eles" (p. 179). A mudança social, portanto, é dependente dessa alteração das consciências dos indivíduos, mediada pela racionalidade, na busca dos interesses individuais e comuns a sua categoria social de pertença, sendo constituída a consciência política, isto é, a politização de identidades sociais. O conflito é uma oposição entre identidades positivas orientadas para realizar a "melhor escolha".

As duas concepções de mudança social (conscientização e consciência política) baseiam-se numa noção sócio-histórica dos sujeitos e conflitiva de sociedade, mas são limitadoras da análise dos fenômenos sócio-políticos. Consideraremos duas limitações.

Uma das limitações é que as duas concepções trazem dificuldades para concebermos a articulação entre diferentes sujeitos políticos em torno de uma utopia de sociedade. Na primeira concepção (conscientização) ressalta-se a construção de uma vontade coletiva, remetendo-se à perspectiva gramsciana de convergência entre lutas da classe subalterna e da classe operária. Entretanto, esta convergência é compreendida à luz de um fundamento último da realidade (as relações de produção), entende-se "que a teoria revolucionária no capitalismo só é possível na ótica de quem produz a mais-valia" (Lane \& Sawaia, 1991, p. 49).

Localizando a contribuição gramsciana para a compreensão da luta política é importante destacar que, como afirmam Laclau e Mouffe (2015), a noção de "vontade coletiva" em Gramsci permitiu ir além da noção de "aliança de classes" proposta por Lênin, pois a constituição da "vontade coletiva" não se trata de uma aliança da classe trabalhadora com outros setores sociais, na qual cada um dos setores participantes mantém sua identidade separada. A "vontade coletiva" em Gramsci implica a constituição de um "bloco histórico" a partir da articulação político-ideológica entre elementos que em si mesmos não pertenciam necessariamente a nenhuma classe, produzindo uma unidade sociocultural a partir da qual vontades dispersas se fundam numa concepção de mundo comum (Laclau \& Mouffe, 2015). Neste ponto, Gramsci se afasta do economicismo, pois o sujeito revolucionário não estaria identificado com a classe operária, e sim seria decorrente da articulação políticoideológica, ampliando as possibilidades do discurso da contingência em relação à concepção de "necessidade histórica" que se fazia presente no marxismo clássico. Laclau e Mouffe (2015), entretanto, apontam para uma incoerência no pensamento gramsciano:

Para Gramsci, mesmo que os diversos elementos sociais tenham uma identidade meramente relacional - alcançada por meio de práticas articulatórias -, deve haver sempre um único princípio unificante em toda formação hegemônica e este só pode ser uma classe [econômica] fundamental. (...) a luta política ainda é um jogo de soma zero entre as classes. Este é o cerne essencialista ainda presente no pensamento de Gramsci (p. 134).

Como vemos mantém-se um núcleo economicista no pensamento gramsciano, o qual equivalentemente podemos notar na citação de Lane e Sawaia (1991) na medida em que para as autoras a luta política se constitui a partir da referência à mais-valia. Assim sendo, a prática articulatória é sustentada pela centralidade necessária da economia, ficando outras dimensões políticas subordinadas a este fundamento último da realidade.

Na segunda concepção (consciência política) é possível considerarmos que há uma redução da luta política, a partir das noções de interesse e de identidade social, às particularidades das demandas de cada sujeito, entendidos como positividades. Condição que permite considerarmos uma maior aproximação da luta política ao campo da negociação pela conquista de interesses particulares numa lógica de maximização do bem-estar individual e grupal do que à centralidade da articulação entre diferentes grupos sociais subalternizados na construção de um imaginário social alternativo ao hegemônico.

A segunda limitação refere-se à vinculação entre teoria e prática. As duas concepções pressupõem, em última instância, o intelectual como legislador ou como 
pedagogo na compreensão da luta política: legislador, ao reduzirem a realidade à centralidade das relações econômicas, no primeiro caso, e a dinâmica política à racionalidade, no segundo caso; pedagogo, ao permitirem estipular o desenvolvimento da consciência dos indivíduos, seja da falsa consciência ou da consciência ideologizada à consciência verdadeira, no primeiro caso, seja da consciência do senso comum à consciência revolucionária, no segundo caso.

Em razão dessas duas limitações, propomos deslocamentos teóricos a partir de uma perspectiva não essencialista que pressupõe que todo objeto é constituído como objeto de discurso num campo geral da discursividade. Esta perspectiva baseia-se numa ontologia negativa que implica uma radicalidade social e histórica dos sujeitos e da sociedade por conceber ambos como vazios de significado a priori, sendo caracterizados não pela existência de um "ser", mas exatamente por uma "falta a ser" (Laclau, 2005a).

\section{A Identificação como Processo de Constituição dos Sujeitos e da Mudança Social}

A perspectiva não-essencialista que apresentamos fundamenta-se em concepções de Laclau e de Mouffe sobre a politização das relações sociais. Nesta perspectiva os sujeitos constituem-se como posições de sujeito (Laclau, 1993) a partir da identificação com discursos presentes no contexto em que vivem, que permitem preencher o vazio da plenitude do social e de sua própria falta a ser. Entretanto, essa constituição somente se realiza como um esforço de fixação parcial, contingente e precário, pois, como não existe um plano das essências e um plano das aparências, é necessário abandonar "a premissa da 'sociedade' como uma totalidade suturada e autodefinida" (Laclau \& Mouffe, 2015, p. 185, itálico no original) e a premissa dos sujeitos como determinados por qualquer forma de essencialismo.

As relações políticas são entendidas como relações antagônicas, o que significa que se os sujeitos se constituem como posições de sujeito no interior de um discurso, sua única possibilidade de emergência como sujeito político ocorre no próprio momento do conflito a partir de uma relação de negatividade. Sendo os sujeitos e a sociedade vazios de significado a priori, a politização das relações sociais ocorre não por uma autoconsciência sobre o fundamento último da realidade ou por um autoconhecimento que permita uma decisão baseada na "melhor escolha" e em atributos e interesses que definem identidades e relações adversárias anteriores ao conflito. Uma relação antagônica é aquela que demonstra os limites de toda objetividade e, assim, que a fixação da objetividade como universal decorreu de uma relação de negatividade com alternativas discursivas que necessitaram ser excluídas por impedir essa fixação, ao mesmo tempo, que são constitutivas do seu interior, pois, na ausência de qualquer essência, a única possibilidade de existência de uma objetividade é pela negatividade.

Neste sentido, compreende-se que a fixação de uma objetividade como universal significa a hegemonia de determinada construção discursiva contingente. Hegemonia é entendida como um tipo de relação caracterizada pela convergência entre objetividade e poder, pois aquela fixação implica a exclusão de discursos alternativos e, portanto, relações de poder, sendo o poder entendido não como fundacional, definido a priori a partir de um centro, e sim como construído através de lógicas sociais contingentes (Laclau \& Mouffe, 2015). O campo da hegemonia é o das práticas articulatórias entre conteúdos ou demandas políticas antagônicas, sendo, portanto, construído a partir da delimitação de fronteiras políticas instáveis, de modo que a própria identidade das forças antagônicas é submetida a constantes redefinições.

A politização das relações sociais ocorre, desse modo, mediante a subversão da ordem social hegemônica, revelando ser esta apenas um esforço discursivo parcial e precário de nomeação da realidade, e, portanto, incapaz de preencher a plenitude da sociedade, possibilitando formas de vida que questionem seu fundamento ontológico. Essa subversão é mediada não pela racionalidade, e sim pela identificação dos sujeitos com um discurso antagônico ao discurso hegemônico que disputa com esse a significação dos princípios vazios de liberdade e igualdade fomentados pelo imaginário democrático. Este imaginário é entendido como um novo modo de instituição do social que emergiu com a revolução francesa, a partir da afirmação do poder absoluto do povo e da dissolução dos marcos de referência da certeza que definiam um fundamento último do poder, do saber e da lei (Lefort, 1991). De acordo com Laclau e Mouffe (2015), este imaginário

forneceu as condições discursivas que permitiriam conceber diferentes desigualdades como ilegítimas e antinaturais, tornando-as assim equivalentes como formas de opressão. Aqui está o poder profundamente subversivo do discurso democrático, que permitiu a expansão da igualdade e da liberdade 
para domínios cada vez mais vastos, e atuou como elemento de fermentação sobre diferentes formas de luta contra a subordinação (pp. 238-239).

Esse novo modo de instituição do social, se permitiu a expansão da democracia a diferentes âmbitos sociais, não predetermina a direção das lutas políticas, abrindo caminho, diante do rompimento com os essencialismos e a afirmação do campo político como contingente, para articulações políticas diversas, não existindo um caráter necessariamente progressista nas lutas (Laclau \& Mouffe, 2015). Os princípios democráticos de liberdade e igualdade podem ser articulados de distintas maneiras, inclusive na disputa pela própria definição de uma mesma luta democrática como o feminismo, o antirracismo, o anti-capitalismo, dependendo isso do modo que se constrói o antagonismo. Assim, o caráter das lutas está na articulação discursiva e não na positividade dos sujeitos ou da sociedade.

O processo de mudança social nesta perspectiva, portanto, depende da subversão da formação social hegemônica e da reconstrução das relações sociais, estabelecendo outras relações hegemônicas. O problema do político é, deste modo, "o problema da instituição do social, isto é, da definição e articulação das relações sociais num campo atravessado por antagonismos" (Laclau \& Mouffe, 2015, p. 236).

Assim, o político refere-se à disputa pela significação da realidade, mas não a partir da revelação de uma consciência verdadeira (conscientização) ou do desenvolvimento da consciência dos indivíduos (consciência política), e sim da construção de um discurso antagônico ao discurso hegemônico no campo de abertura possibilitado pelos princípios democráticos da igualdade e da liberdade. Essa disputa não pode ser resolvida racionalmente, pois seus limites não são empíricos ou epistemológicos, mas ontológicos, uma vez que constitutivos de formas de vida que emergem na relação antagônica. A identificação discursiva em um terreno ontológico não essencialista, e não a racionalidade, é o elemento mediador da politização das relações de dominação, não sendo possível determinar de antemão os sujeitos políticos e o desenvolvimento da história.

$\mathrm{Na}$ inexistência de uma essencialidade da sociedade e, assim, de uma centralidade das relações sociais, essa perspectiva parte da compreensão de que há uma pluralidade de espaços políticos e que esses não se remetem a nenhuma base unitária última. Desse modo, uma formação social é constituída a partir de uma pluralidade de relações hegemônicas, podendo a subversão do discurso hegemônico ocorrer em torno de qualquer posição na cadeia discursiva hegemônica, sendo o espaço político entendido como o espaço de emergência do antagonismo (Laclau \& Mouffe, 2015). Assim, há uma variedade de antagonismos possíveis que podem proporcionar uma pluralidade de lutas democráticas, as quais, a partir de articulações contingentes entre demandas políticas distintas, podem construir equivalências democráticas, caracterizadas por delimitar um discurso capaz de abranger uma pluralidade de relações sociais.

Importante ressaltar que as relações de subordinação em si mesmas não são relações antagônicas, pois somente estabelecem um conjunto de posições de sujeito diferenciais entre os agentes. O antagonismo só pode emergir através da subversão desse caráter diferencial:

\footnotetext{
'Servo', 'escravo' etc., não designam em si posições antagonísticas; somente em termos de uma diferente formação discursiva, tal como 'os direitos inerentes a todo ser humano', é que a positividade diferencial dessas categorias pode ser subvertida e a subordinação construída como opressão. Isto significa que não existe relação de opressão [relações de subordinação que se transformaram em relações antagônicas] sem a presença de um 'exterior' discursivo a partir do qual o discurso da subordinação possa ser interrompido" (Laclau \& Mouffe, 2015, p. 237).
}

Nesta perspectiva teórica, a demanda política construída pelos sujeitos é concebida desde o início como dividida, sendo, ao mesmo tempo, particular, pois constituída a partir da politização de uma determinada relação de subordinação; e equivalencial, pois construída de maneira antagônica e, assim, passível de se articular a outras demandas políticas também antagônicas à ordem social sedimentada a fim de instituir uma alternativa contra-hegemônica de sociedade. O conteúdo desta alternativa não é determinado a priori, mas construído na articulação equivalencial com outras lutas democráticas, a qual altera a natureza de cada um dos sujeitos da cadeia equivalencial sem, contudo, extinguir a particularidade de suas demandas, pois essas são equivalentes e não iguais. Trata-se de uma articulação em torno de um significante que alcança um caráter de singularidade e que representa a plenitude ausente presente no discurso hegemônico para todos os sujeitos políticos da cadeia equivalencial. 
Como exemplo de politização das relações de subordinação podemos pensar a situação das travestis na sociedade brasileira. Discursos hegemônicos como o binarismo de gênero negam a elas o direito à igualdade e à liberdade que o imaginário democrático reconheceu como princípios para todos. Essa negação implica relações de subordinação que podem ser rearticuladas como uma relação de opressão mediante a subversão do discurso hegemônico a partir da identificação com o imaginário democrático. O binarismo de gênero pode ser subvertido pela impossibilidade dele abarcar a existência da travesti na cadeia discursiva, e, portanto, preencher plenamente o vazio do social, pois a existência da travesti coloca em questão o próprio fundamento do discurso binário: a coerência entre sexo e gênero. Assim, mediante a identificação com o imaginário democrático, faz-se possível a construção de um discurso antagônico pelas travestis que rearticule a relação entre sexo e gênero a fim de possibilitar uma pluralidade de existências dos sujeitos.

Em outro âmbito social, por exemplo, o da relação de trabalho, diferentemente de uma compreensão marxista que pressupõe, como apontamos antes, que "a história da humanidade é a história da luta de classes" (Mendonça, 2014, p. 79), concebe-se ser necessário um discurso exterior à relação de trabalho que impeça a estabilização da relação de subordinação como um diferença para que ela emerja como uma relação antagônica. A identificação com o discurso democrático de igualdade e liberdade para todos permite a politização das relações de trabalho ao, diante da impossibilidade do trabalhador alcançar condições dignas de vida, propiciar a construção de uma alternativa discursiva que articule os princípios democráticos de um modo antagônico ao discurso que sustenta aquela relação de subordinação. Neste sentido, por exemplo, antagonicamente a um discurso que entende a igualdade como igualdade de oportunidades no terreno da livre competição, poderíamos ter a construção de um discurso que conceba a igualdade como igualdade de condições e os direitos individuais como direitos que só podem ser exercidos coletivamente, supondo direitos iguais para todos. Para Laclau e Mouffe (2015), as demandas socialistas são um momento interno da revolução democrática, sendo fruto do deslocamento da crítica à desigualdade política para a desigualdade econômica.

Nos dois exemplos não há uma concepção dos sujeitos como positividades, sendo enfatizado a necessidade da identificação com um discurso externo - imaginário democrático, por exemplo - à relação de subordinação para que esta possa ser transformada em uma relação de opressão. As diferentes relações sociais que atravessam as posições de sujeito acarretam em possibilidades distintas de subversão da hegemonia e não há como determinar a direção das lutas democráticas.

Ademais, as demandas das travestis ou dos trabalhadores podem ser rearticuladas pelo próprio discurso hegemônico a partir de estratégias da hegemonia que visem invisibilizar as fronteiras políticas, reduzindo a relação antagônica a uma relação diferencial, colocando fim ao conflito. Entretanto, as demandas podem também ser concebidas pelas travestis e pelos trabalhadores como objetivos parciais na construção de uma alternativa antagônica de sociedade, possibilitando, inclusive, equivalências entre elas na construção de outro horizonte de sociedade em razão de terem se constituído antagonicamente à hegemonia. Como afirma Laclau (2003), as demandas podem ser vistas como

objetivos determinados que, uma vez alcançados, colocam fim ao movimento. No entanto, podese vê-las de uma forma diferente: o que as demandas apontam não é na realidade aos objetivos concretamente especificados; elas são somente a ocasião contingente de alcançar (de um modo parcial) algo que as transcende completamente: a plenitude da sociedade como um objeto impossível que - através da sua própria impossibilidade - se faz totalmente ético [investimento em outro imaginário social] (pp. 90-91, tradução nossa).

Na perspectiva da conscientização, correríamos o risco de reduzir, em última instância, as demandas a interesses determinados pelas posições dos sujeitos nas relações econômicas. No caso da perspectiva da consciência política, correríamos o risco de reduzir as demandas ao seu caráter particular por tratá-las como decorrentes do auto-interesse e dos interesses relativos à categoria social a qual estivessem vinculados os sujeitos. Nesse sentido, a resolução do conflito poderia se dar pela negociação dos interesses contrários dos grupos em disputa sem que fosse implicada na análise a possibilidade de construção de uma cadeia de equivalência entre as demandas em torno de uma alternativa contra-hegemônica de sociedade.

No primeiro caso teríamos o essencialismo da totalidade social, no segundo caso a dispersão de posições de sujeito suturadas, o que faz também pressupormos a noção de totalidade social. Ambas saídas impedem conceber a construção de articulações contingentes contra-hegemônicas. 


\section{Do Lugar do Intelectual para o Lugar da "Ação Intelectual"}

Na impossibilidade de afirmarmos a essencialidade dos sujeitos e da sociedade, qual o lugar da ação intelectual e, assim, da relação entre teoria e prática na luta política?

A psicologia social crítica latino-americana questionou a dicotomia sujeito-objeto, afirmou o caráter relacional, dialógico e horizontal entre pesquisador e pesquisado. Entretanto, o foco na noção de consciência possibilita-nos pensar o pesquisador como aquele que detém a consciência a ser alcançada pelos indivíduos em condição de dominação.

A proposta de deslocamento nesse imaginário crítico fundamenta-se em compreender a politização das relações de subordinação não a partir da noção de consciência, e sim de identificação, e, nesse caso, o lugar do intelectual não há como ser o de legislador ou de pedagogo. Será o lugar de compreender as demandas políticas produzidas pelos sujeitos em uma determinada sociedade a fim de contribuir para a expansão de discursos democráticos e para a potencialização da equivalência entre demandas, ainda que não saibamos se ocorrerão e que mundo será construído.

Essa proposta retoma a noção de hegemonia no interior da psicologia social, mas na crítica a um fundamento último da realidade. A mudança social está ligada a uma relação entre o universal e o particular que não possibilita escolher entre o abandono do universal e o abandono das demandas particulares, e sim enfatizar que a mudança social está completamente relacionada ao destino do universal e à pluralidade de sujeitos políticos. O desafio democrático é potencializarmos equivalências democráticas em um determinado contexto histórico.

Nessa medida, nossa proposta coaduna-se com a compreensão de Laclau e Mouffe (2015) que a tarefa da esquerda é aprofundar e expandir o discurso democrático a toda a sociedade civil e ao Estado, sendo a multiplicação de espaços políticos e o impedimento da centralidade do poder pré-condições de uma transformação democrática da sociedade. Como afirmam os autores, "Não há, por exemplo, vínculos necessários entre antissexismo e anticapitalismo, e uma unidade entre ambos só pode ser resultado de uma articulação hegemônica." (Laclau \& Mouffe, 2015, p. 266, itálico no original). Como fruto de uma articulação, "não há uma política da esquerda cujo conteúdo possa ser determinado na ausência de toda referência contextual" (p. 267, itálico no original).
Um exemplo apresentado por Laclau (2005b) auxilia-nos a pensar o vínculo entre teoria e prática que propomos para a psicologia social: potencializar contiguidades que possam vir a se concretizarem em analogias, nos termos que utilizamos, potencializar equivalências entre demandas políticas.

Imaginemos um determinado bairro onde existe violência racial e as únicas forças locais capazes de organizar uma contra-ofensiva antirracista são os sindicatos. Agora bem, em um sentido estritamente literal, a função dos sindicatos não é lutar contra o racismo, mas negociar os salários e outras questões similares. No entanto, se a campanha antirracista é empreendida por sindicatos, é porque existe uma relação de contiguidade entre as duas questões em um mesmo bairro. Uma relação de deslocamento entre termos, problemas, atores, etc. é o que se denomina, em retórica, uma metonímia. Suponhamos agora que esta conexão entre lutas antirracistas e sindicais continue por certo período de tempo: neste caso, vamos começar a sentir que existe um vínculo natural entre os dois tipos de luta. Assim, a relação de contiguidade vai começar a se converter em uma relação de analogia, a metonímia em uma metáfora. Este deslocamento retórico implica três mudanças principais: primeiro, apesar do particularismo diferencial dos tipos iniciais de lutas e demandas, se está criando entre eles certa homogeneidade equivalencial. Segundo, a natureza dos sindicatos se modifica neste processo: deixam de ser a pura expressão de interesses setoriais precisos e se voltam em maior medida - se desenvolve uma variedade de articulações equivalenciais - ao ponto nodal na constituição de um "povo". Terceiro, a palavra "sindicato" se converte no nome de uma singularidade, no sentido em que a temos definido antes: já não designa o nome de uma universalidade abstrata e se converte no nome de um agente social concreto, cuja única essência é a articulação específica de elementos heterogêneos que, mediante este nome, cristaliza uma vontade coletiva unificada (pp. 140-141, tradução nossa).

Diante destas considerações um aspecto ainda é importante de ser enfatizado: o deslocamento do lugar do intelectual se faz pertinente em conjunto com o questionamento do próprio lugar dos sujeitos políticos na produção do conhecimento. Na atualidade, a partir da crítica às grandes narrativas, da concepção do descentramento do espaço político e dos sujeitos, da construção de articulações globais e locais entre 
movimentos sociais é cada vez mais urgente reconhecer estes sujeitos como "produtores intelectuais" que, inclusive, interpelam a própria produção científica. Neste sentido, ao abordarmos o lugar do intelectual não o fazemos a fim de reafirmar uma posição de superioridade em relação aos sujeitos políticos, podendo este lugar ser assumido por estes próprios sujeitos. A pertinência deste debate está exatamente em concebermos a importância da academia contribuir para a expansão de discursos democráticos, vinculando teoria e prática. Talvez estejamos no momento no qual os termos precisam ser deslocados em convergência com nossas posições e, assim, ao invés de "lugar do intelectual" passemos a utilizar, como o fizemos ao longo deste texto, "o lugar da ação intelectual", pois passível de ser ocupado tanto pelos movimentos sociais quanto pela academia.

\section{Considerações finais}

Propusemos refletir sobre a relação entre crítica, política e psicologia social a partir da discussão sobre a noção de mudança social e do lugar da ação intelectual na luta política na atualidade. Para tanto, construímos possibilidades de deslocamentos em duas concepções teóricas presentes na psicologia social crítica brasileira, os quais implicam novos olhares para a compreensão e intervenção da/na realidade.

Apesar das diferenças teóricas relativas à proposta de psicologia social crítica de Lane e Sawaia (1991), compartilhamos com as autoras que a psicologia social "tem contribuições essenciais para a compreensão e interpretação política numa sociedade." (p. 05). Como apontamos, a compreensão dos sujeitos e da sociedade como vazios de significados a priori permite radicalizarmos o caráter social e histórico de ambos e, assim, afirmarmos a importância da análise psicossociológica dos fenômenos sócio-políticos. Butler (2013), ao pensar a crítica sob a ausência de certezas epistemológicas, pergunta: "o que há de bom em um pensar diferente se não sabemos de antemão se esse pensar produzirá um mundo melhor?" (p. 163). Concebemos que a inexistência dos marcos de referência de certeza impossibilita-nos saber de antemão que caminho será percorrido, mas longe de ser pessimista, a proposta apresentada neste artigo permite-nos reconhecer que nenhum projeto político é inabalável e, portanto, potencializar uma pluralidade de perspectivas credíveis de mundo (Laclau, 1996).

Neste sentido, a crítica apresentada a concepções presentes na psicologia social crítica brasileira está aberta a tornar-se objeto criticado na disputa pela construção deste campo de conhecimento e, assim, pela compreensão dos fenômenos sociais e pela afirmação de outros imaginários sociais.

\section{Referências}

Álvaro, J. L., \& Garrido, A. (2006). Psicologia social: Perspectivas psicológicas e sociológicas. São Paulo: McGraw-Hill.

Bomfim, E. (2003). Psicologia social no Brasil. Belo Horizonte: Edições do Campo Social.

Butler, J. (2013). O que é a crítica? Um ensaio sobre a virtude de Foucault. Cadernos de Ética e Filosofia Política, 22, 159-179. Recuperado de http://www.revistas.usp.br/cefp/article/view/59447/62615

Camino, L. (1996). Uma abordagem psicossociológica no estudo do comportamento político. Psicologia \& Sociedade, 8(1), 16 42. Recuperado de http://abrapso.org.br/siteprincipal/index. php? Itemid=38\&id=19\&option=com_content\&sectionid=6\&task= category

Camino, L., \& Torres, A. R. R. (2011). Origens e desenvolvimento da psicologia social. In L. Camino A. R. R., Torres; M. E., O. Lima; \& M. E. Pereira (Orgs.), Psicologia social: Temas e teorias (pp. 23-99). Brasília: Technopolitik.

Codo, W. (1985). Ideologia: o ponto fundamental da discussão. Psicologia: Ciência e Profissão, 5(1), 18-20. doi: 10.1590/S141498931985000100009

Farr, R. (2006). As raízes da psicologia social moderna. Petrópolis: Vozes.

Gonçalves, B. D. (2008). Impactos da participação e da consciência política na vida de mulheres líderes em política. Pesquisas e Práticas Psicossociais, 3(2), 199-213. Recuperado de http://www.seer.ufsj. edu.br/index.php/revista_ppp/article/view/510/474

Laclau, E. (1993). Nuevas reflexiones sobre la revolución de nuestro tiempo. Buenos Aires: Ediciones Nueva Visión.

Laclau, E. (1996). Beyond Emancipation. In E. Laclau (Org.), Emancipation(s) (pp. 01-19). Londres/Nova York: Verso.

Laclau, E. (2003). Identidad y hegemonia: El rol de la universalidade en la constitución de lógicas políticas. In J. Butler, E. Laclau, \& S. Zizek (Orgs.), Contingencia, hegemonía, universalidad: diálogos contemporáneos en la izquierda (pp. 49-93). Buenos Aires: Fondo de Cultura Económica de Argentina.

Laclau, E. (2005a). Desconstruction, pragmatism, hegemony. In C. Mouffe (Org.), Descontruction and pragmatism (pp. 49-70). Londres e Nova lorque: Routledge.

Laclau, E. (2005b). La razón populista. Buenos Aires: Fondo de Cultura Económica de Argentina.

Laclau, E, \& Mouffe, C. (2015). Hegemonia e estratégia socialista. Por uma política democrática radical. São Paulo: Intermeios; Brasília: CNPq

Lane, S. T. M. (1987a). A psicologia social e uma nova concepção do homem para a psicologia. In S. T. M. Lane \& W. Codo (Orgs.), Psicologia social: o homem em movimento (pp. 10-19). São Paulo: Editora Brasiliense.

Lane, S. T. M. (1987b). Consciência/alienação: a ideologia no nível individual. In S. T. M. Lane \& W. Codo (Orgs.), Psicologia social: o homem em movimento (pp. 40-47). São Paulo: Editora Brasiliense.

Lane, S. T. M. (1987c). O processo grupal. In S. T. M. Lane \& W. Codo (Orgs.), Psicologia social: o homem em movimento (pp. 78-98). São Paulo: Editora Brasiliense. 
Lane, S. T. M. (1995). Avanços da psicologia social na América Latina. In S. T. M Lane \& B. B. Sawaia (Orgs.), Novas veredas da psicologia social (pp. 67-81). São Paulo: Brasiliense: EDUC.

Lane, S. T. M., \& Sawaia, B. B. (1991). Psicologia: ciência ou política? In M. Montero (Org.), Acción y discurso (pp. 05-69). Venezuela: Eduven.

Lefort, C. (1991). Pensando o político: ensaios sobre democracia, revolução e liberdade. Rio de Janeiro: Paz e Terra.

Mendonça, D. (2014). A impossibilidade da emancipação: notas a partir da teoria do discurso. In D. Mendonça \& L. P. Rodrigues (Orgs.), Pós-estruturalismo e teoria do discurso: em torno de Ernesto Laclau (pp. 75-91). Porto Alegre: ediPUCRS.

Montero, M. (2010). Crítica, autocrítica y construcción de teoria en la psicologia social latinoamericana. Revista Colombiana de Psicologia, 19(2), 177-191. Recuperado de http://www.revistas.unal.edu.co/ index.php/psicologia/article/view/13156/34432

Moscovici, S. (2003). Sociedade e teoria em psicologia social. In S. Moscovici (Org.), Representações sociais: investigações em psicologia social (pp. 111-166). Petrópolis, RJ: Vozes.
Rodrigues, A. (1985). Ciência e tecnologia a serviço do homem. Psicologia: Ciência e Profissão, 5(1), 18-20. doi: 10.1590/S141498931985000100007

Sandoval, S. A. M. (1989). Considerações sobre aspectos micro-sociais na análise dos movimentos sociais. Psicologia \& Sociedade, 4(7), 61-72. Recuperado de http://www.abrapso.org.br/conteudo/ view?ID_CONTEUDO=539

Sandoval, S. A. M. (2002). O que há de novo na psicologia social latino-americana. In R. H. Campos \& P. Guareschi (Orgs.), Paradigmas em psicologia social: a perspectiva latino-americana (pp. 101-109). Petrópolis, RJ: Vozes.

Sandoval, S. A. M. (2015). A psicologia política da crise do movimento sindical brasileiro dos anos 1990: uma análise da consciência política num momento de desmobilização. In A. S. Silva \& F. Correa (Orgs.), No interstício das disciplinaridades: A psicologia política (pp. 175217). Curitiba: Prismas.

Silva, A. S. (2007). A identificação de adversários, de sentimentos antagônicos e de (in)eficácia política na formação da consciência política no MST paulista. Estudos e Pesquisas em Psicologia, 7(1), 102-123. Recuperado de http://pepsic.bvsalud.org/scielo.php?script=sci_ arttext\&pid=S1808-42812007000100010\&lng=pt\&tlng=pt.

\footnotetext{
${ }^{1}$ Reconhecemos que há uma pluralidade de "marxismos" na produção das ciências humanas e sociais. O que queremos enfocar neste debate é a definição do desenvolvimento histórico e dos sujeitos políticos a partir da centralidade das relações de produção, sendo o projeto emancipatório compreendido a partir de critérios a priori. Já se conhece o sujeito a ser emancipado, pois ele já está dado a partir da concepção de que "a história da humanidade é a história da luta de classes e na fase atual capitalista os opressores são os burgueses e os oprimidos são os proletários" (Mendonça, 2014, p. 79).

${ }^{2}$ Interessante também considerar a proposta psicossociológica de Camino (1996), que propõe afastar-se da aplicação direta de categorias do materialismo histórico-dialético na compreensão do comportamento político, recorrendo à perspectiva das relações intergrupais, sobretudo, à teoria da identidade social de Henry Tajfel. Duas considerações são importantes: a) esse afastamento não implicou no abandono da redução dos sujeitos políticos às relações econômicas; b) a teoria de Tajfel é uma perspectiva racionalista e concebe os sujeitos como positividades. Sandoval também é influenciado pela teoria da identidade social (Silva, 2007).
} 
Crítica, política e psicologia social

Frederico Alves Costa, Doutor em Psicologia pela Universidade Federal de Minas Gerais (UFMG), Pós-doutorando (PNPD/CAPES) no Programa de Pós-Graduação em Psicologia da Universidade Federal de Alagoas (UFAL), é Professor no Programa de Pós-Graduação em

Psicologia da Universidade Federal de Alagoas (UFAL). Endereço para correspondência: Avenida João Davino, 306, apto 802, Jatiúca,

Maceió, Alagoas. CEP: 57.035-554. Telefones: (082) 99919 3244/

(031) 98840 2185. E-mail: fredericoalvescosta@gmail.com

Marco Aurélio Máximo Prado, Doutor em Psicologia Social pela Pontifícia Universidade Católica de São Paulo (PUC/SP), Pós-doutorado pela Fulbright Foundation na Universidade of Massachusetts, é Professor Associado III do Departamento de Psicologia da Universidade Federal de Minas Gerais (UFMG) e Professor no

Programa de Pós-Graduação em Psicologia da Universidade Federal de Minas Gerais (UFMG). E-mail: mamprado@gmail.com 